\title{
Ice-age storage of respired carbon in the Pacific Ocean
}

\author{
Allison W. Jacobel', R.F. Anderson², B.A.A. Hoogakker³ and S.L. Jaccard ${ }^{4}$
}

\begin{abstract}
Proxy-based reconstructions of oceanic dissolved oxygen and carbon concentrations have helped to refine our understanding of past ocean-atmosphere carbon partitioning, consistently indicating lower dissolved oxygen in the deep Pacific Ocean during the last ice age. Better quantitative and spatio-temporally resolved estimates of these parameters are critical for closing the carbon budget and elucidating the relative importance of the mechanisms and feedbacks driving past carbon exchange among Earth's carbon reservoirs.
\end{abstract}

Over at least the last $800 \mathrm{kyr}$, glacial-interglacial cycles have been characterized by variations in atmospheric $\mathrm{CO}_{2}$ concentrations of 50-100 ppm (Bereiter et al. 2015 and references therein). The glacial drawdown of atmospheric $\mathrm{CO}_{2}$ is thought to be largely a consequence of changes in southern highlatitude surface-ocean processes including increased $\mathrm{CO}_{2}$ solubility, enhanced watercolumn stratification, decreased air-sea gas exchange, improved efficiency of the biological pump, and heightened ocean alkalinity (e.g. Sigman et al. 2010). One way to tease apart these mechanisms is to reconstruct relative changes in the carbon storage of the ocean's various water masses, especially those which have biogeochemical signatures strongly influenced by processes occurring in the Southern Ocean that are propogated to other basins. Not only do these reconstructions help provide insight into the relative importance of different airsea carbon exchange mechanisms, they also help us to balance the global carbon budget by quantifying how much additional carbon was stored in the glacial ocean.

Until recently, consensus on the significance of glacial respired carbon storage in the Pacific Ocean was hampered by conflicting interpretations procured in part from ${ }^{14} \mathrm{C}$-derived water-mass ventilation ages, taken to be indicative of carbon accumu lation in the abyssal ocean. Numerous caveats to the ventilation age approach have been identified in recent years (e.g. Zhao and Keigwin 2018), suggesting that direct reconstructions of water-mass carbon and oxygen concentrations are a more straightforward way to avoid these interpretive challenges. Indeed, proxy reconstructions focused on dissolved oxygen and respired carbon consistently demonstrate the key role of respired carbon storage in the Pacific Ocean and its role in glacial atmospheric $\mathrm{CO}_{2}$ minima (e.g. Anderson et al. 2019; Hoogakker et al. 2018; Jaccard and Galbraith 2012; Jacobel et al. 2017). With this consensus, subsequent work has turned towards quantifying the total storage, parsing its distribution among the basin's various water masses, and investigating the role of mechanisms driving the observed changes. Important questions remain about whether the relative distributions of carbon and oxygen that characterize the modern ocean (Fig. 1) were maintained during the last ice age despite overall higher carbon storage and lower oxygen availability.

\section{Dissolved carbon and oxygen in the ocean} One of the early approaches to reconstructing respired carbon in bottom waters utilized the $\delta^{13} \mathrm{C}$ of epibenthic foraminifera tests, in which progressive $\delta^{13} \mathrm{C}$ depletion along a water-mass trajectory is interpreted as indicative of increased respiration of organic carbon (e.g. Curry and Oppo 2005). Unfortunately, air-sea disequilibrium in water-mass source regions can complicate the interpretation of this signal (Galbraith et al. 2015). Oxygen equilibrates an order of magnitude faster than carbon, and because of the tight stoichiometric relationship between oxygen and respired carbon (imparted by the consumption of oxygen and concomitant release of carbon during microbial respiration), the deviation of dissolved oxygen concentrations from saturation levels is the most direct and quantitative paleoceanographic variable for reconstructing changes in deep-sea carbon storage (Sigman et al. 2010). While the air-sea equilibration of oxygen in water mass source areas may be incomplete (Ito et al. 2004), any undersaturation at the time of water-mass formation would lead to an underestimation of respiratory $\mathrm{CO}_{2}$ storage (for more detail see Anderson et al. 2019). This results in paleoceanographic estimates that reflect a conservative assessment of changes to respired carbon sequestration through time.

\section{Proxy toolbox}

Although reconstructing dissolved oxygen concentrations is an advantageous way to quantify respired carbon storage, finding simple proxies, especially quantitative ones, has been challenging. Early reconstructions examined sedimentary enrichments in redox-sensitive metals including $\mathrm{Cd}, \mathrm{Cr}$, $\mathrm{Mn}, \mathrm{Mo}, \mathrm{Re}$, and most notably $\mathrm{U}$. One of the

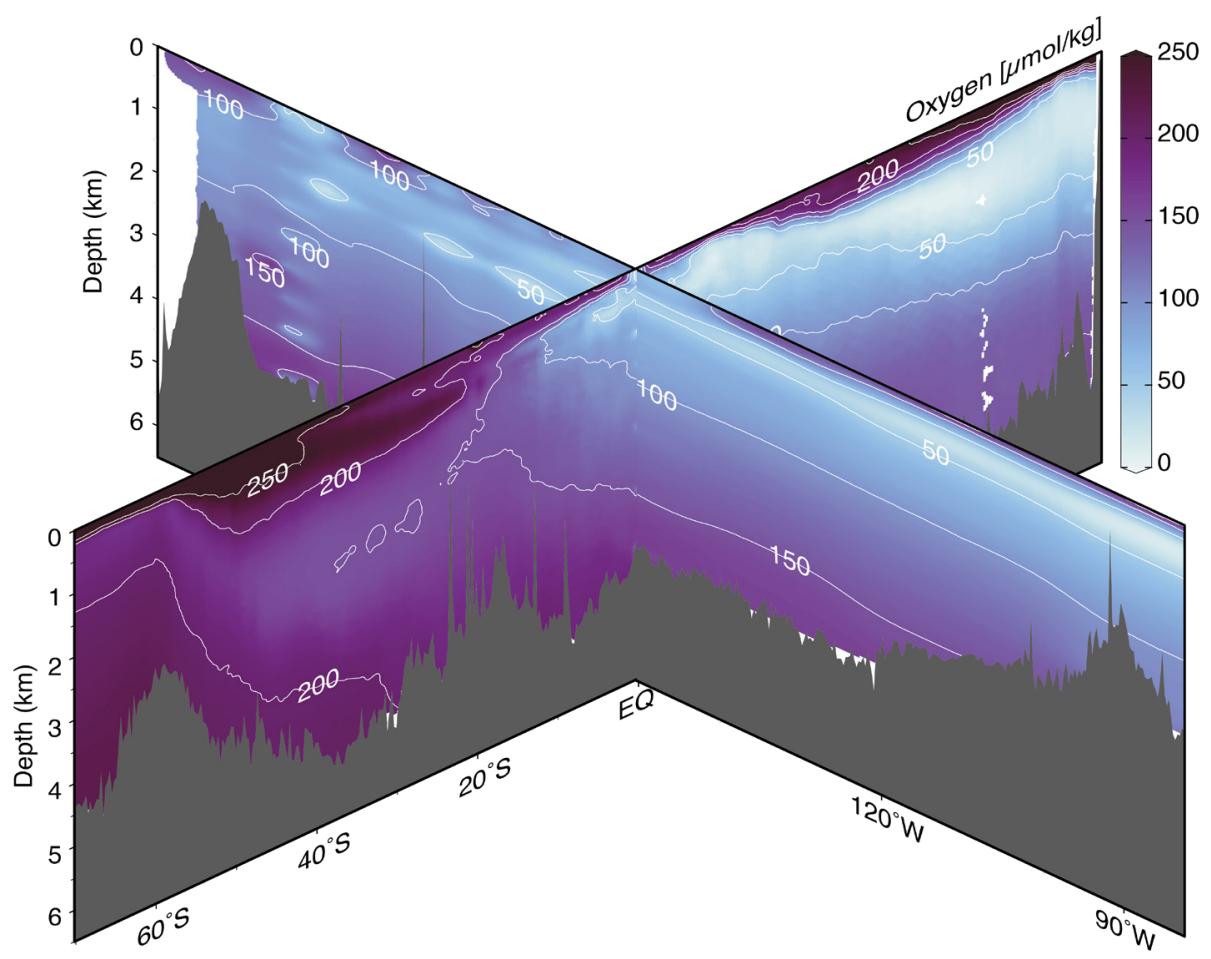

Figure 1: Modern distribution of oxygen in the Pacific Ocean. South-to-north transect from $150^{\circ} \mathrm{W}$ and west-to east transect along the equator. Data from the PACIFICA dataset (Suzuki et al. 2013). Figure composed using Ocean Data View with in situ data gridded using data-interpolating varational analysis (Schlitzer 2018). 


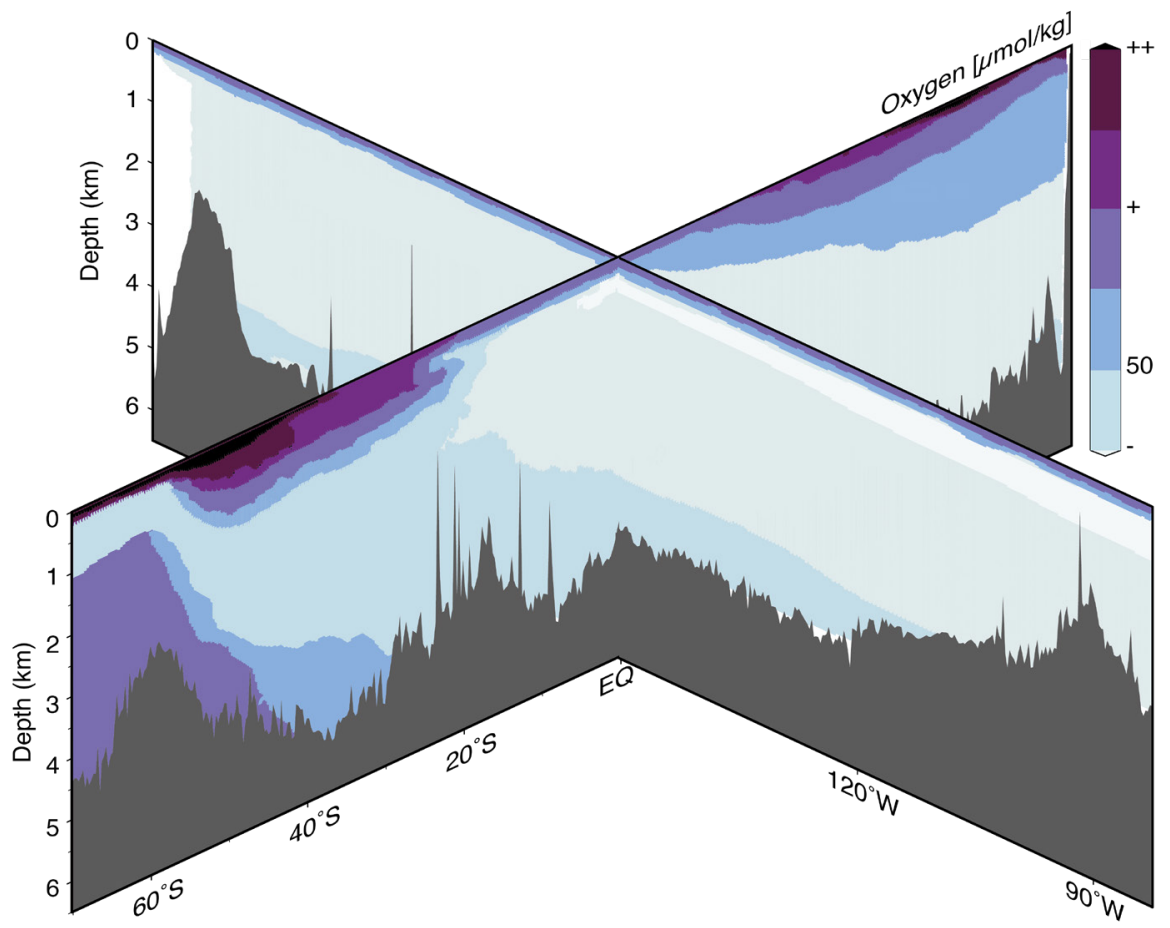

Figure 2: Schematic representation of the distribution of oxygen during the Last Glacial Maximum in the Pacific Ocean based qualitatively on model results and paleo reconstructions. Additional spatial and quantitative constraints are needed to refine this conceptual picture.

reasons for the popularization of authigenic $\mathrm{U}(\mathrm{a} U)$ as a bottom-water oxygen proxy is because it is a product of U/Th series measurements made to quantify mass fluxes to the seafloor using the ${ }^{230} \mathrm{Th}$-normalization method. Under reducing (i.e. anoxic) conditions soluble $\mathrm{U}(\mathrm{VI})$ is transformed to insoluble $\mathrm{U}(\mathrm{IV})$ and is precipitated from porewaters, likely by iron-reducing microbes (McManus et al. 2005). If the co-occurring flux of organic carbon to the sediments can be established (to control for the typically confounding effect of microbial respiration on porewater oxygen concentrations), changes in the sedimentary abundance of $\mathrm{aU}$ can be interpreted qualitatively as indicative of changes in bottom-water oxygen availability. Because the post-depositional re-introduction of oxygen can remove aU from sediments, careful attention must be paid to avoid interpreting diagenetic artifacts introduced by down-core diffusion of oxygen and subsequent aU loss (e.g. Jacobel et al. 2017).

Recently, two proxies for quantitatively reconstructing bottom-water oxygen have evolved in parallel. The first is grounded in observations made in the 1980s (McCorkle et al. 1985) suggesting that the carbon isotope gradient in porewaters is, at least in part, related to bottom-water oxygen concentrations. The proxy was recently calibrated by Hoogakker et al. (2015) and empirically relates the carbon isotope gradient $\left(\Delta \delta^{13} \mathrm{C}\right)$ between epifaunal benthic foraminifera and infaunal benthic species to the bottom-water oxygen concentration. The second proxy, most recently detailed by Anderson et al. (2019), makes use of the semi-quantitative relationship between oxygen availability and the remineralization of organic matter (for example the $\mathrm{C}_{37}$ alkenone biomarker) by oxic respiration. As with aU, both the $\triangle \delta^{13} \mathrm{C}$ and biomarker preservation proxies may respond to the rain of labile organic carbon to the site. Thus, reconstructions of bottom-water oxygen content should always be presented alongside, and interpreted in tandem with, a diagenesisresistant, flux-normalized proxy for organic carbon flux such as biogenic (or excess) barium or opal flux.

\section{Findings}

Numerous records of aU, $\triangle \delta^{13} \mathrm{C}$, and $\mathrm{C}_{37}$ biomarker preservation have been measured at Pacific Ocean sediment core sites, especially in the equatorial Pacific, where sites provide good coverage of the basin's deep water masses. Where multiple proxies have been measured on co-located samples, general agreement on the sense and timing of bottom-water oxygen changes has been found (Anderson et al. 2019), despite some site-specific data limitations due to changes in the rate of organic carbon fluxes, or postdepositional diagenesis. Importantly, lower oxygen concentrations during the last ice age have been found for all deep equatorial Pacific sites below $\sim 1 \mathrm{~km}$ (Anderson et al. 2019), suggesting that the entire deep Pacific below the depth of the modern oxygen minimum zone experienced increased respired carbon storage (see schematic in Fig. 2). Data from the high latitude North and South Pacific Oceans are consistent with findings from the equatorial Pacific (e.g. Jaccard and Galbraith 2012; Jaccard et al. 2009). The latest conservative estimates based on the biomarker preservation proxy (Anderson et al. 2019) suggest that $\mathrm{CO}_{2}$ storage during the last ice age may have been up to $\sim 850 \mathrm{PgC}$ greater than at present. This estimate is based on the assumption that the magnitude of carbon storage in the deep equatorial Pacific during the last ice age is representative of $50 \%$ of the ocean's volume - an extrapolation that, while reasonable, reflects the scarcity of quantitative estimates of ocean carbon storage. Although additional data are needed to better constrain the uncertainties associated with this estimate, deep ocean carbon storage of this magnitude is sufficient to close the glacial carbon budget by accounting for both estimates of atmospheric $\mathrm{CO}_{2}$ drawdown and estimates of carbon loss from the terrestrial biosphere.

\section{Future work}

Advances in proxy development and interpretation represent significant progress towards the goal of quantitatively reconstructing respired carbon storage in abyssal Pacific water masses and in those of the other ocean basins during the last ice age and other past climate intervals. As paleoceanographers push these reconstructions to become more robust and spatio-temporally resolved, their ability to provide insight into past changes increases, and their role in validating models of glacial-interglacial change that include biogeochemical cycles (e.g. Khatiwala et al. 2019; Yamamoto et al. 2019) is enhanced. As the global oceans experience increasing impacts from anthropogenic climate forcing, improving biogeochemical models of ocean responses is ever more crucial. Using past variability in climate states as experimental realizations for testing hypotheses about mechanisms of change is critical for improving predictions and targeting preventative and mitigating action.

\section{AFFILIATIONS}

'Department of Earth, Environmental and Planetary Sciences, and Institute at Brown for Environment and Society, Brown University, Providence, RI, USA 2Lamont-Doherty Earth Observatory, and Department of Earth and Environmental Sciences, Columbia University, New York, NY, USA

${ }^{3}$ The Lyell Centre, Heroit-Watt University, Edinburgh, UK

${ }^{4}$ Insitute of Geological Sciences, and Oeschger Center for Climate Change Research, University of Bern, Switzerland

\section{CONTACT}

Allison Jacobel: jacobel@brown.edu

\section{REFERENCES}

Anderson RF et al. (2019) Global Biogeochem Cy 33: 301-317

Bereiter B et al. (2015) Geophys Res Lett 42: 542-549 Curry WB, Oppo DW (2005) Paleoceanography 20: PA1017

Galbraith ED et al. (2015) Global Biogeochem Cy 109 38-48

Hoogakker BAA et al. (2015) Nat Geosci 8: 40-43 Hoogakker BAA et al. (2018) Nature 562: 410-413 Ito T et al. (2004) Geophys Res Lett 31: L17305 Jaccard SL et al. (2009) Earth Planet Sc Lett 277: 156-165 Jaccard SL, Galbraith ED (2012) Nat Geosci 5: 151-156 Jacobel AW et al. (2017) Nat Commun 8: 1727 Khatiwala S et al. (2019) Sci Adv 5: eaaw4981 McCorkle DC et al. (1985) Earth Planet Sc Lett 74: 13-26 McManus J et al. (2005) Geochim Cosmochim Ac 69 95-108

Schlitzer R (2018) Ocean Data View

Sigman DM et al. (2010) Nature 466: 47-55

Suzuki T et al. (2013) PACIFICA Data Synthesis Project

Yamamoto A et al. (2019) Clim Past 15: $981-996$

Zhao N, Keigwin LD (2018) Nat Commun 9: 3077 